\title{
PISTRAK E MARX: OS FUNDAMENTOS DA EDUCAÇÃO RUSSA
}

\author{
Carlos Lucena ${ }^{1}$ \\ Robson Luiz de França² \\ Fabiane Santana Previtali ${ }^{3}$ \\ Antônio Bosco de Lima ${ }^{4}$ \\ Adriana Omena ${ }^{5}$
}

\section{RESUMO:}

Este artigo analisa o pensamento educacional de M. M. Pistrak (1888-1937) no início do século XX na Rússia. Demonstra o contexto da instauração da revolução bolchevique, os elevados índices de analfabetismo e miséria, debatendo a necessidade de reconstrução russa a partir de bases econômicas, políticas e sociais antagônicas ao capitalismo em sua fase monopolista. A apropriação dos resultados do trabalho concreto e abstrato pelo conjunto da sociedade é entendida como primordial para a construção de uma sociedade superior. É nesse sentido que demonstramos a influência de pressupostos epistemológicos marxianos na obra de Pistrak, apontando a revolução enquanto um processo educativo e emancipatório da humanidade.

Palavras-chave: M. M. Pistrak; Educação Russa; Karl Marx; Socialismo; Trabalho.

\section{PISTRAK AND MARX: THE FUNDAMENTALS OF RUSSIAN EDUCATION}

\begin{abstract}
:
This article examines the educational thought of M. M. Pistrak (1888-1937) at the beginning of the twentieth century in Russia. Demonstrates the context of the establishment of the Bolshevik revolution, the high rates of illiteracy and poverty, arguing the need to rebuild the Russian bases from economic, political and social antagonistic to capitalism in its monopoly stage. The appropriation of the results of concrete and abstract work by the whole society is understood as essential to building a superior society. In this sense, we demonstrate the influence of epistemological assumptions in the work of Marxist Pistrak, pointing to the revolution as a process of education and emancipation of humanity. Keywords: M. M. Pistrak, Russian Education, Karl Marx, Socialism, Work.
\end{abstract}

\section{Introdução}

M. M. Pistrac (1888-1937) ${ }^{6}$ viveu em um período histórico revolucionário marcado pela construção da revolução bolchevique e do socialismo russo no início do século XX. Influenciado pelo pensamento de Karl Marx, Friedrich Engels, Nadéjda Krupskaia, Pavel Blonsky, Vassili Lunatcharsky, Vassili Sukhomlinski, Vladimir Lenin, participou de um amplo processo de transformação social que teria, entre seus pressupostos, a reconstrução da sociedade e da educação aos pressupostos econômicos, políticos e sociais do socialismo. As promessas de crescimento social na Europa e nos Estados Unidos, o advento das crises do capitalismo ${ }^{7}$, as novas técnicas de produção industrial, apontavam continuidades e rupturas, mediações e contradições que se manifestavam em processos materializados pela história em transformação e movimento. 
A revolução Russa de 1917 foi acompanhada por uma intensa guerra civil nos quatro anos, proporcionando a fome e destruição em todo o país. O contexto de conflitos e de profundas transformações sociais impulsionou o debate sobre a negação de concepções educacionais tsarista-verbalistas até então existentes no país (Freitas, 2009, 11).

[...] a grande revolução socialista de outubro abriu ante Pistrak e outros professores horizontes avançados e imensos para a aplicação de suas forças, conhecimentos e habilidades na criação da nova escola do trabalho. Quando o Comissário Nacional de Educação (o NarkomPros) começou começou a organização das primeiras escolas comunascomunas, Pistrak foi trabalhar na Escola Comuna P. N. Lepeshinskiy junto a pedagogos tão entusiastas como ele: R. M. Mikelson (professor de Ciências naturais e de Economia rural, posteriormente - membro da academia das Ciências Pedagógicas da Rússia, diretor do Instituto de Pesquisa Científica de Pedagogia de Latvia); A. I. Strazhev (professor de História, conhecido metodólogo, posteriormente membro da Academia de Ciências pedagógicas da Rússia; E. A. Berezanskaia (Professora de Matemática, autora conhecida de materiais didáticos e exercícios de Aritmética) e outros. M. M. Pistrak trabalhou por cinco anos como professor da Comuna. Estes foram anos de árduo trabalho, os quais o conduziram, e ao coletivo de pedagogos e seus educandos, aos primeiros resultados positivos, ainda que pequenos, mais perceptíveis, e à confiança da vitalidade da escola socialista (Freitas, 2009, 18).

Uma nova concepção de educação foi pensada voltada para a formação do homem integral, proporcionando esperança e participação social, condição fundamental para o avanço do socialismo. Esse palco de esperança e de transformação social era exemplificado pelo otimismo existente nos anos 1923 e 1924 através das ações concretas da Comissão de Menores no combate às crianças de rua vítimas de "insuficiência moral"

[...] entre os quais se classificam os pequenos ladrões de rua, os jovens batedores de carteira, etc. Recolhem-se nos cortiços e nas casas de cômodo bandos completos de crianças já solidamente organizados na base de uma luta original pela existência, quadrilhas de ladrões (que praticam furtos e o roubo), batedores de carteira, e também, muitas vezes, viciados em cocaína, que já estão no ramo há três ou quatro anos, pequenas prostitutas, etc. Os bandos são presos em conjunto com os chefes (uma espécie de atamã). Não são desmembrados, mas convertidos em pequenas comunas de trabalho. Exigem-se, de modo geral, três condições: não roubar, não tomar cocaína, desenvolver um trabalho produtivo, útil à maioria, de forma a ganhar, assim, uma parte do pão cotidiano. A colônia dispõe de uma casa comum e um ou dois administradores ficam com ela. Um dos objetivos da organização é quebrar a autoridade absoluta do chefe, baseada na força, substituindo-a pela autoridade do coletivo, encarregado de criar sua vida e sua própria organização. As experiências deste tipo, de acordo com os resultados obtidos em alguns meses, superam em certos casos, todas as expectativas. O coletivo é tão unido que, por exemplo, não há necessidade de fechar a chave o almoxarifado (anteriormente, cada fugitivo, sem exceção, levava um travesseiro e um cobertor para vender); os casos de fuga quase não se verificam mais (às vezes, entretanto, o chefe deposto não pode se conter). A marca social que caracteriza a atividade das crianças, o sentimento de que sua vida tem um sentido social, objetivando grandes finalidades 
sociais, fortalece o coletivo infantil; tornam-se conscientes de sua dignidade e se unem estreitamente. Conhecemos um caso bastante interessante numa dessas comunidades, entrou, sorrateiramente, durante uma noite escura, um pequeno ladrão, logo descoberto pelas crianças. A comuna persuadiu-o a ficar em igualdade de direitos. Ele aceitou. [...] Qual a origem, porém do êxito? É que estes viciados em cocaína, ladrões, prostitutas de 12 anos, etc., que foram levianamente classificados na categoria de crianças "marcadas por insuficiência moral" e irremediavelmente perdidas, são, na realidade, crianças brilhantes, ativas, capazes, de grande iniciativa, mas pervertidas pela vida, e que encontram condições quando o coletivo infantil tem a possibilidade de se desenvolver, de crescer pelos seus próprios meios e de se organizar numa base social. Tudo se explica pelo coletivo infantil (Pistrak, 2000: 195196).

O processo revolucionário russo teve contornos através de uma intensa participação dos trabalhadores. A Rússia possuía no início do século XX a maior população da Europa, algo em torno de 174 milhões de habitantes, acompanhados de sérios problemas sociais como a ausência de terra para os camponeses e a precariedade das condições de trabalho dos operários. A ascensão dos bolcheviques ao poder significou a necessidade de profundas transformações nas relações sociais presentes até então. Era necessário reconstruir um país com limitações de inserção internacional, ausência de tecnologias, de produção industrial, excluído pela dinâmica mundializada do imperialismo que se manifestava na luta entre os grandes Trustes internacionais ao acesso a mercados consumidores e matérias-primas como tão bem analisou Lênin em "Imperialismo: fase superior do capitalismo".

Entendia-se a necessidade de reconstrução de um país sobre novas bases negando os princípios capitalistas imperantes. É nesse sentido que se configuravam afirmações da internacionalidade do movimento dos trabalhadores: o velho mundo desmorona-se e um novo mundo nasce. Transformar um país quase todo analfabeto em uma nação soberana baseada nos princípios do socialismo real, era um dos grandes desafios colocados por Lênin. A Rússia e a construção gradativa de União Soviética atraíam socialistas de todos os países interessados na construção de uma proposta única até então, que poderia se transformar em um embrião da internacionalização do socialismo.

\section{Alguns pressupostos do pensamento educacional de Pistrak.}

As contradições presentes no processo de construção da Revolução Russa dão fundamentos para a problematização do pensamento de Pistrak sobre a educação. A crítica ao capitalismo implicava na defesa da escola como o instrumento principal para a formação de uma consciência de classe dos trabalhadores para o futuro assentada na importância e na revolução como um caminho sem volta.

É preciso que a nova geração compreenda qual a natureza da luta travada pela humanidade, qual o espaço da classe explorada e qual o espaço que deve ser ocupado por cada adolescente, e que cada um saiba em seus respectivos espaços travar a luta pela destruição das formas inúteis, substituindo por um novo edifício (Pistrak, 2000: 31).

Partindo do princípio que a revolução socialista materializava o estágio mais avançado de toda a história da humanidade, Pistrak entendia que a religião, o trabalho rural baseado no arado manual e a rotação trienal significavam ruínas que existiam apenas no 
passado. O presente significava a negação de um passado social, econômico e político atrasado a ser esquecido, pois a revolução socialista era um caminho sem volta. O presente é manifestado através de avanços tecnológicos e sociais do seu tempo - tais qual o telégrafo sem fio e a cooperação, a eletrificação e a Internacional Comunista, as comunicações aéreas entre Moscou e a China - que deveriam ser incorporados pelo conjunto da população: o entendimento do uso social da ciência como desdobramento das mediações do homem com a natureza.

Nas diferentes e complexas dimensões entre o passado e o presente, a educação era central no processo de transição, uma vez que entre a escola revolucionária e escola antiga havia apenas uma continuidade dialética e revolucionária, da mesma forma que o novo regime nasce do antigo graças a suas contradições internas. "A escola refletiu sempre o seu tempo e não podia deixar de refleti-lo; sempre esteve a serviço das necessidades de um regime social determinado e, se não fosse capaz disso, teria sido eliminada como um corpo estranho inútil" (Pistrak, 2000: p.29). Com efeito, a escola teria como objetivo,

[...] estudar a realidade atual, penetrá-la, viver nela. Isto não quer dizer, certamente, que a escola não deva estudar as ruínas do passado: não, deve estudá-las e assim será feito, mas com a compreensão de que são apenas ruínas do passado e de que seu estudo deve ser iluminado à luz da realidade atual no sentido já indicado acima, à luz da luta travada contra o passado e da transformação da vida que deve à sua liquidação (Pistrak, 2000: p.33)

A educação era entendida por Pistrak como uma poderosa ferramenta capaz de fomentar a construção do socialismo na Rússia, devendo romper com os preceitos do capitalismo. O que estava em jogo era a formação integral do homem, reinventando a cultura e novos princípios formativos do e para o mundo. Os conteúdos do ensino oferecidos às novas gerações teriam o papel de armar a criança para a construção de uma nova ordem, com novos conhecimentos e concepções sobre a sociedade. É por isso que a educação deveria se desenvolver para além dos conteúdos escolares, explorando e problematizando as mediações dialéticas com a sociedade do presente. ${ }^{8}$

O trabalho na escola, enquanto base da educação, deve estar ligado ao trabalho social, à produção real, a uma atividade concreta socialmente útil, sem o que perderia seu valor essencial, seu aspecto social, reduzindo-se, de um lado, à aquisição de algumas normas técnicas, e, de outro a procedimentos metodológicos capazes de ilustrar este ou aquele detalhe de um curso sistemático. Assim, o trabalho se tornaria anêmico, perderia sua base ideológica (Pistrak, 2000: p.38).

A articulação da educação com a sociedade tem como pressuposto o entendimento da centralidade das relações da humanidade para com a natureza que se desenvolvem através da problematização do significado do conceito de trabalho tão bem elaborados por Marx e Engels. A humanidade se reconhece através dessa mediação, se organiza socialmente, dá sentido e coloca objetivos em sua existência. ${ }^{9}$

O que estava em jogo era a recuperação de pressupostos marxianos inerentes à potencialização da educação para a construção do socialismo. Pistrak era influenciado por Marx no entendimento da educação enquanto um amplo processo de formação do homem. A educação é elaborada a partir das determinações concretas da sociedade capitalista, assumindo a contradição do trabalho no processo de produção capitalista em que há a 
negação do homem e, ao mesmo tempo, a criação de condições para a emergência de um novo homem. Discutir o conceito de educação em Marx significa abordar aspectos que são fundamentais e, ao mesmo tempo, presentes em uma totalidade. Em primeiro lugar, a união entre o ensino e o trabalho como uma ferramenta para a construção de um novo homem. Em segundo lugar, a negação da escola burguesa (iluminista) vista como um instrumento de legitimação de uma classe sobre outra. Por último, o conceito da revolução como um fenômeno educativo.

Numa concepção de ensino socialista, Marx relaciona o ensino e o trabalho produtivo, unindo o primeiro ao segundo. A educação socialista acabaria com a separação entre intelectuais e trabalhadores, pois esta separação impedia o trabalho de ter acesso ao saber e controlar o processo de produção e reprodução dos conhecimentos científicos. Para Marx, o saber unindo-se ao fazer faria com que os operários ultrapassem os limites do senso comum, destruindo as barreiras entre eles e o conhecimento fabril.

Marx defende que a base técnica da grande indústria diferencia o artesanato da manufatura que o precedeu. A mesma é uma base revolucionária em que a moderna ciência, baseada na tecnologia que elabora e elimina com igual rapidez as formas dos processos de produção, provoca mudanças no trabalho e na produção. Esse processo faz com que o trabalhador seja cada vez mais parcial.

O universo do trabalho não supõe apenas elementos práticos, ou meros treinamentos técnicos (aprendizagem de um ofício), mas, supõe um embasamento teórico para explicar os elementos daquele universo ainda bastante inexplorado. Daí porque Marx e Engels insistem que a participação dos operários na produção esteja intimamente associada à formação intelectual (Jesus, 1998: p. 49).

De acordo com Souza Júnior (1997), a discussão fundamental da educação em Marx se localiza no processo educativo do proletariado, único meio que se pode passar da alienação universal à sociabilidade dos homens livres. Para Marx, a organização do proletariado é um processo educativo fundamental, no qual se destacam, como questões importantes, o papel das associações operárias, dos partidos, dos sindicatos, etc., e ocupa o papel de destaque o conceito de revolução. Com efeito, o trabalho é fundamental, pois é a partir dele que Marx aposta num amplo revolucionar dos homens. O trabalho tem um caráter educativo, essencial à trajetória do ser humano rumo a sua emancipação. ${ }^{10}$

Marx não admite uma concepção idealista da educação. Defende a libertação do homem em todos os sentidos, fundindo o campo e a cidade, o ensino e a produção, etc.,. A classe operária é a portadora da ciência do futuro que só se materializará via processo de ruptura com o capitalismo, pois a plena educação cultural das massas não pode ser realizada numa sociedade dividida em classes sociais. Com efeito, Marx critica o ensino iluminista, que atenta à manutenção e aos interesses de uma classe social específica, que projeta aos homens o seu referencial e projeto de sociedade.

"Todo o sistema de ensino da sociedade capitalista assenta no racionalismo burguês, ou seja, um idealismo ou iluminismo que esclarece os espíritos, as massas e a matéria (...) a sociedade dividida em duas classes é necessariamente idealista: a elite esclarecida dita as normas, e a massa bruta deve segui-las sem discussão (Dangeville apud. Marx \& Engels, 1978: p.35). 
O ensino iluminista apenas reproduz para o futuro as condições de saber e de ignorância indispensáveis ao bom andamento do capital. Daqui resulta a sua divisão fundamental.

\begin{abstract}
Apresentar o ensino como um meio que se oferece a todos, como uma oportunidade de subida social, oferecida no alvorecer da vida, independentemente da origem social dos indivíduos, é típico da abstrata e oca democracia burguesa e procede uma dupla mistificação, que só tem influência sobre os pequenos burgueses que oscilam entre as classes exploradoras e a explorada. Para a maioria, que só nos interessa numa visão de classe, o ensino apenas reproduz para o futuro as condições do saber e da ignorância, indispensáveis ao bom andamento do capital. Daqui resulta a sua divisão fundamental em ensino elementar obrigatório e ensino superior, abandonando as crianças mais favorecidas o primeiro a partir da idade de 10 - 11 anos. A seleção feroz (que explica a angústia e por vezes revolta dos jovens) é feita por grosso a partir da base econômica e não da inteligência igualmente repartida potencialmente em todas as classes, dispondo as crianças dos ricos de um meio material que as prepara muito naturalmente para a ideologia $\mathrm{e}$ as reações "dominantes', , e as pobres vivendo no estado que reproduz a pobreza, não condizendo as suas condições com o que lhes é ensinado na escola (Marx \& Engels, 1978: p. 38).
\end{abstract}

Marx defende na Ideologia Alemã que a civilização capitalista se desenvolve sobre um fundo de ignorância. A riqueza de alguns é função da pobreza das massas. A divisão do trabalho existente desenvolve, nos que têm uma profissão, uma única faculdade ou um único tipo de gesto em detrimento de todas as outras potencialidades do homem. Com referência à instrução burguesa dos operários, Marx e Engels afirmam que, por sorte,

[...] as condições em que vive esta classe asseguram-lhe uma formação prática, que não só substitui toda a incoerência escolar, mas ainda neutraliza o efeito pernicioso das idéias religiosas confusas de que está revestido o ensino - e é isto mesmo que coloca os operários à frente do movimento de toda a Inglaterra. A miséria não ensina apenas o homem a orar, mas ainda muito mais: a pensar e a agir (Idem, p. 69).

O conceito do pensar e do agir, de se apropriar das condições de miséria e exclusão, levam os homens a atuarem no intuito de transformarem a sua condição de vida. É por isso que o projeto de transformação social não pode ser compreendido como algo neutro, pois a transformação é fruto de uma aprendizagem no conflito, da constatação de que é somente mudando a sociedade que as relações sociais se transformarão. Dentro de uma concepção marxiana de educação, a revolução é um processo educativo fundamental para o futuro, que deve ser compreendido como uma totalidade, fruto de determinações históricas e materiais. Ela representa uma instância educativa no interior da qual o processo revolucionário se localiza e aparece como um dos processos contraditórios. A revolução é um processo educativo, um movimento engendrado por determinadas forças históricas, por uma determinada forma de vida social após atingido certo desenvolvimento que, em si, já é um processo amplo de educação. Embora seja a revolução a educação decisiva, a única forma possível para superar a alienação burguesa, a mesma não é o único processo educativo, nem surge isolada dos processos sociais. Ela não só é educadora do homem, como imprescinde de uma educação prévia para se realizar. Ela é a auto transformação do homem, é práxis humana, atividade finalista que intervém transformando as circunstâncias 
em relação com as quais o homem se constrói. "As considerações do desenvolvimento histórico do homem como amplo processo educativo, bem como da revolução como educação do homem para novas relações sociais, não podem surgir como pura especulação, como resultado de meras elucubrações sem nenhuma base concreta que lhes dê sustentação" (Jesus, 1997: p.145).

Marx entendia que o ensino deveria propiciar aos trabalhadores condições de resistir aos males da divisão do trabalho, da alienação e das condições precárias do trabalho. A educação deveria ser constituída como um instrumento para a realização da luta histórica dos trabalhadores que os elevasse acima das demais classes. Para isso, os trabalhadores deveriam ter como missão a ruptura com a escola iluminista., visto que o mesma representa, sob o domínio capitalista, "uma arma de mistificação e de conservação entre as mãos da classe capitalista. Tem tendência para dar aos jovens uma educação que os torna leais e resignados ao sistema atual, e os impede de descobrir as suas contradições internas" (Dangeville apud. Marx \& Engels, 1978: p.37). ${ }^{12}$

Estes pressupostos epistmológicos marxianos foram fundamentais para a construção dos fundamentos educacionais presentes no pensamento de Pistrak. A articulação entre o trabalho e a educação é condição fundamental para os processos de formação humana. Nesse sentido, a relação entre a teoria e a prática são pressupostos entendidos como pilares para a formação do homem integral. O que se problematiza aqui é a importância da práxis humana como elemento formativo.

A estratégia defendida por Pistrak para a formação dos alunos russos tem como referência processos educativos baseados no desenvolvimento de oficinas formativas educacionais que potencializariam a percepção da revolução e a necessidade de construção da revolução socialista sobre novas bases.

Conferimos uma enorme importância à criação técnica. Toda criação, técnica, científica, artística, é a aptidão para combinar subconscientemente os elementos constitutivos que contribuem para a produção do objeto que se quer criar, e a aptidão para escolher instintivamente numa série de combinações aquelas que são melhores. Qualquer homem possui tais aptidões em maior ou menor grau: é preciso que a escola as desenvolva por todos os meios à sua disposição, e este é o objetivo dos novos métodos pedagógicos baseados na atividade e na investigação do aluno. A criação técnica está longe de ocupar o último lugar entre os diversos tipos de criação. Mas este tipo de criação é particularmente importante numa época como a nossa, caracterizada por uma construção rápida e pelo estabelecimento das bases de um novo regime. Se não dispusermos de uma juventude ativa, curiosa, e totalmente apta para a criação técnica, uma juventude capaz de construir um novo mundo mais rapidamente e melhor do que nós, será impossível transformar o conjunto da nossa economia, para que supere, no correr dos próximos anos, o progresso técnico da Europa ocidental e da América (Pistrak, 2000: p.62).

Para Pistrak, a fábrica é o agente em que se desenvolviam todas as contradições da realidade no início do século XX. Ela é um centro complexo de relações sociais, sendo fundamental a atenção da escola na formação dos alunos para essa questão. As crianças deveriam desenvolver a sua criatividade estudando ao lado dos operários como aprendizes, colaborando com a produção e, ao mesmo tempo, conhecendo a fábrica em todas as suas partes, condição fundamental para a percepção do trabalho de forma científica. "a base da educação comunista é antes de tudo o trabalho imaginado na perspectiva de nossa vida 
moral, o trabalho concebido do ponto de vista social, na base do qual se forja inevitavelmente uma compreensão determinada da realidade atual, o trabalho introduz a criança desde o início na atividade socialmente útil". (Pistrak, 2000: 105-106)

Pistrak entendia que as crianças deveriam tocar as matérias primas em transformação, compreendendo

[...] as diversas vantagens do progresso ao nível das máquinasferramentas e das máquinas-motrizes. É preciso participar do trabalho para compreender a essência para a divisão do trabalho. Para compreender o trabalho de uma máquina, é preciso sentir diretamente o que é de fato a mecanização da produção. Ora, a oficina profissional pode propiciar tudo isso (Pistrak, 2000: p.59).

Estas afirmações ressaltam os diálogos com os escritos de Marx sobre a grande indústria, nos quais o advento da tecnologia não é entendido como um fim em si mesmo, mas sim como uma força social que impulsionaria profundas transformações em seu tempo. ${ }^{13}$

As contradições constatadas entre o avanço tecnológico e a miserabilidade crescente dos trabalhadores tomam como referência a expansão da maquinaria industrial e a elevação da obtenção de mais-valia absoluta e relativa, estratégias legitimadas por uma acumulação crescente e incontrolável do capital, independente do custo social que essa ação signifique. Marx demonstra que o capital possui uma tendência a consolidar o desenvolvimento total das forças produtivas. A consolidação desse processo coloca ao próprio capital a necessidade de ultrapassar constantemente os limites por ele mesmo criados. Dialogando com a lei do contato dos extremos apontada por Hegel, aponta que o modo de produção capitalista possibilita que locais distantes no planeta se relacionem, toquem-se e se liguem, potencializando a existência de pólos de prosperidade e riqueza justificados por pólos de pobreza em regiões distintas no planeta. As condições miseráveis existentes em países percussores do capitalismo na Europa, como a Inglaterra e a França no século XIX, só foram superadas pela organização dos trabalhadores através da luta de classes por um lado, e pelo incremento da exploração de outras nações ainda não industrializadas por outro.

Incorporando os princípios marxianos referentes à ciência e a tecnologia, Pistrak aponta que o grande desafio da ciência enquanto força humanizadora do presente para o futuro passa pela construção gradativa da apropriação dos seus resultados de forma social e não privada.

A defesa de uma escola humanizadora tendo referência a articulação dialética entre a teoria e a prática atua como negação à precariedade educativa oferecida aos trabalhadores na Europa denunciados por Marx em "O Capital". ${ }^{14}$ A luta contra o analfabetismo travado na Rússia tinha como princípio a negação de uma sociedade de classes que gradativamente negava o acesso ao saber aos filhos dos proletários, concretizando separação radical entre o saber e o fazer. A luta contra um pressuposto central denunciado por Marx e Engels ainda no período manufatureiro referente à divisão social dos ramos de atividades, atacando os trabalhadores nas próprias raízes de suas vidas. "Subdividir um homem, é executá-lo se mereceu uma sentença de morte, mas é assassiná-lo, se não o merece. A divisão do trabalho é o assassínio de um povo" (1978: 202-203). ${ }^{15}$

Marx afirma em os "Grundisse" que os trabalhadores se transformam em acessórios conscientes das máquinas. O trabalhador comporta-se como um acessório vivo da máquina, um mero meio de ação para uma atividade estranha a ele mesmo. "A ciência do capitalismo não existe mais no cérebro dos trabalhadores, pelo contrário, se manifesta nas 
máquinas que agem sobre os trabalhadores como uma força estranha, como o próprio poder da máquina" (Marx, 1980: 39).

\begin{abstract}
A máquina já não tem nada de comum com o instrumento do trabalhador individual. A atividade manifesta-se muito mais como pertencente à máquina, ficando o operário a vigiar a ação da máquina e protegê-la de avarias. Com a ferramenta era diferente. $O$ trabalhador animava a ferramenta com sua arte e criatividade. Com efeito, a máquina é que passa a ter virtuosidade, pois as leis mecânicas em seu interior dotaramna de alma. (...) Nos numerosos pontos do sistema mecânico, o trabalho aparece como corpo consciente, sob a forma de alguns trabalhadores vivos. Dispersos, submetidos ao processo de conjunto da maquinaria, não forma mais do que um elemento do sistema, cuja unidade não reside nos trabalhadores vivos, mas na maquinaria viva (ativa) que, em relação à atividade isolada e insignificante do trabalho vivo, aparece como um organismo gigantesco (Marx, 1980: 38-39). ${ }^{16}$
\end{abstract}

O pensamento de Pistrak e seus diálogos apresentados com a obra marxiana apontam desafios aos educadores presentes no campo socialista. A negação dos pressupostos inerentes à sociedade capitalista nos parece primordial. O pensamento de Pistrak responderia às questões colocadas na sociedade atual? Entendemos que sim, até porque, em nosso entendimento, a história não chegou ao seu fim e é movimentada pelos conflitos e luta de classes. Aos educadores se coloca a seguinte questão tão bem debatida por Marx e Engels em crítica à Feuerbach e a Ideologia Alemã "Os filósofos têm apenas interpretado o mundo de maneiras diferentes, a questão é transformá-lo".

\title{
Bibliografia
}

BRAVERMAM, H. Trabalho e Capitalismo Monopolista. Rio de Janeiro: Zahar, 1980. 379p.

DANGEVILLE, ROGER. Introdução e notas. In MARX, K; ENGELS, F. Crítica da educação e do ensino. Lisboa: Moraes, 1978.

ENGELS, F. Anti-During, 2001. http://www.pstu.org.br/biblioteca/engels_antiduhring.pdf acesso dia 10/05/2007 às 18:00 horas.

A dialética da natureza. São Paulo: Paz e Terra, 1991.

FREITAS, L. C. A luta por uma pedagogia do meio: revisando o conceito. In Pistrak. M. M. A escola comuna.SP: Expressão Popular, 2009.

JESUS, Antônio Tavares de. O Pensamento e a Prática Escolar de Gramsci.

Campinas, São Paulo: Autores Associados, 1998. 129p.

LUCENA, Carlos. Marxismo, crise do capitalismo monopolista e qualificação dos trabalhadores. In Lombardi, J. C.; Saviani Dermeval (orgs). Marxismo e Educação: debates contemporâneos. Campinas, SP: Autores Associados, 2005.

MANACORDA, M. A. Marx y la pedagogía moderna. Barcelona, Espanha : Oikos-tau Ediciones, 1979. 
MARX, K. Grundisse. In MARX K. Obras Completas: conseqüências sociais do avanço tecnológico. SP: Edições Populares, 1980.

1966.

O Capital - crítica de la economia política. México: Fondo de Cultura Econômica,

O Capital: crítica da economia política. Livro $1^{0}$, Volume I, tradução Regis Barbosa e Flávio R. Kothe. - 2. ed - São Paulo: Ed. Nova Cultural, 1985.

O Capital: crítica da economia política._Livro $1^{\circ}$, Volume II, tradução Regis Barbosa e Flávio R. Kothe. - 3. ed. - São Paulo: Ed. Nova Cultural, 1988.

O Capital: crítica da economia política. Livro $2^{\circ}$, Volume III, tradução Reginaldo Sant' Anna - 3. ed. - São Paulo: Ed. Nova Cultural, 1984.

O Capital: crítica da economia política. Livro $3^{\circ}$, Volume VI, tradução Reginaldo Sant' Anna - 3. ed. - São Paulo: Ed. Nova Cultural. 1984.

. (s/d) Capítulo VI inédito de O Capital. SP: Moraes.

. Elementos fundamentais para la crítica de la economia política. Grundisse. Argentina: Siglo XXI Argentina Editores, 1973.

- Miséria de la filosofia: respuesta a la filosofia de la miséria de P. - J. Proudhon. México: Siglo Veintiuno Editores, 1987.

. (2006) Sobre o suicidio. SP: Boitempo Editorial.

MARX, K, ENGELS, F. A ideologia alemã. SP: Editora Moraes, 1977.

. . Crítica da educação e do ensino. Moraes Editores, 1978.

. . Manifesto Comunista. SP: Boitempo Editorial, 1998.

PISTRAK, M. Fundamentos da escola do trabalho. SP: Expressão Popular, 2000.

SANTOS, Francisca dos. Educação, Trabalho, Cidadania e Qualidade Social. Revista Trabalho e Educação. Belo Horizonte : n ${ }^{\circ}$ 1, 1997. p. 48-55.

SOUZA JÚNIOR, Hormindo P. Educação, Trabalho, Cidadania e Qualidade Social. Revista Trabalho e Educação. Belo Horizonte : nº 1, 1997

Notas:

\footnotetext{
${ }^{1}$ Professor do Programa de Pós-Graduação em Educação da Universidade Federal de Uberlândia. Integrante da Linha de Pesquisa Trabalho, Sociedade e Educação. Bolsista de Produtividade do CNPQ.

${ }^{2}$ Professor do Programa de Pós-Graduação em Educação da Universidade Federal de Uberlândia. Integrante da Linha de Pesquisa Trabalho, Sociedade e Educação. Pesquisador do CNPQ.

${ }^{3}$ Professora do Programa de Pós-Graduação em Educação da Universidade Federal de Uberlândia. Integrante da Linha de Pesquisa Trabalho, Sociedade e Educação.Pesquisador da Fapemig.

${ }^{4}$ Professor do Programa de Pós-Graduação em Educação da Universidade Federal de Uberlândia. Integrante da Linha de Pesquisa Trabalho, Sociedade e Educação.

${ }^{5}$ Professora do Programa de Pós-Graduação em Educação da Universidade Federal de Uberlândia. Integrante da Linha de Pesquisa Trabalho, Sociedade e Educação.

${ }^{6}$ Pistrak era doutor em Ciências Pedagógicas, professor e membro do Partido Comunista desde 1924. Concluiu a Faculdade de Físico-Matemática na Universidade de Varsóvia em 1914, na Polônia. De 1918 até
}

Revista HISTEDBR On-line, Campinas, número especial, p. 271-282, abr2011 - ISSN: 1676-2584 
1931 trabalhou no Narkompros da União Soviética e, simultaneamente, dirigiu por cinco anos a EscolaComuna do NarKomPros. Entre 1931 e 1936 atuou no Instituto de Pedagogia do Norte do Cáucaso, na cidade de Rostov-na-Donu e, em 1936, foi diretor do Instituto Central de pesquisa Cientifica de Pedagogia junto ao instituto Superior Comunista de educação, do Partido Comunista. Pistrak foi preso em setembro de 1937 durante a perseguição estalinista dos anos 1930; sua morte, por fuzilamento, ocorreu em 25 de setembro de 1937, após permanecer três meses preso, e não em 1940 como foi divulgado 'a época por fontes oficiais (Freitas, 2009, 17/18).

${ }^{7}$ Sobre essa questão o capítulo de Carlos Lucena denominado "Marxismo, crise do capitalismo monopolista e qualificação dos trabalhadores", no livro "Marxismo e Educação: debates contemporâneos", organizado por José Claudinei Lombardi e Dermeval Saviani.

${ }^{8}$ O leitor deve estar atento a essa afirmação. Pistrak possuía todo um conjunto de discussões sobre o que deveria se ensinar nas escolas. O que demonstramos é a educação enquanto um processo de emancipação humana, processo significativo e primordial para a construção da revolução socialista na Rússia. Para maior aprofundamento desta questão ler: M. M. Pistrak. A escola comuna. SP: Expressão Popular, 2009.

${ }^{9}$ Marx afirma em os "Grundisse" que a [...] natureza não constrói máquinas, nem locomotivas, nem estradas de ferro, nem telégrafos elétricos, nem máquinas automáticas de tecer, etc.; isso são produtos da indústria humana, da matéria natural, transformada em instrumentos da vontade e da atividade humana sobre a natureza. São instrumentos do cérebro humano, criados pela mão do homem, órgãos materializados do saber (Marx, 1980: 52). Engels em "O Anti During” problematiza a relação humana com a natureza, afirmando que a liberdade é a expressão da consciência das necessidades naturais, um produto da evolução histórica humana e suas relações com a natureza Os primeiros homens [...] que se levantaram do reino animal eram, em todos os pontos essenciais de suas vidas, tão pouco livres quanto os próprios animais; cada passo dado no caminho da cultura é um passo no caminho da liberdade. Nos primórdios da história da humanidade, realizou-se a descoberta que permitiu converter o movimento mecânico em calor: a produção do fogo pela fricção; o progresso tem, atualmente, como sua etapa terminal, a descoberta que transforma, inversamente, o calor em movimento mecânico: a máquina a vapor. E apesar do colossal abalo de libertação que a máquina a vapor trouxe ao mundo social - e que até hoje ainda não deu sequer a metade de seus frutos - é indubitável que a produção do fogo pela fricção, nos tempos primitivos, foi superior àquela descoberta como condição emancipadora. O fogo, obtido dessa forma, foi que permitiu ao homem o domínio sobre uma força da natureza, emancipando-o definitivamente das limitações do mundo animal (Engels, s/d: 65).

${ }^{10}$ Bravermam (1980) afirma que os trabalhadores só poderão assumir o domínio da produção, assumindo as prerrogativas científicas, de projeto e operacionais da engenharia moderna. O contrário, não haverá domínio do processo produtivo. A vinculação entre a atividade intelectual e prática é o caminho onde encontra-se o princípio educativo que conduz a unidade entre o pensar e o fazer. Isso possibilita o desenvolvimento de uma postura racional voltada para a compreensão e transformação da realidade, condição básica para a formação de um homem superior. Essa dimensão educativa pressupõe refletir sobre as atividades que realizamos, sobre o sentido do trabalho, caracterizar a sua natureza, os seus elementos constituintes e o papel do trabalhador como ser que pensa, que tem clareza dos objetivos a serem alcançados, que busca dominar e aperfeiçoar o processo de trabalho, apropriando-se do produto que é fundamental para a sua vida. Conforme Marx, essa é uma condição indispensável para a conquista da liberdade e da livre criação (Santos, 1997: p. 50).

${ }^{11}$ Aspas do autor.

${ }^{12}$ [...] graças ao ensino, pago pela mais-valia extorquida aos operários durante o tempo livre monopolizado pela classe privilegiada, 'o capitalista torna-se homem social por excelência (desabrochado em condições alienadas), e representa a civilização'. A fim de que não subsista nenhuma dúvida sobre a natureza infecta e alienada desta civilização das sociedades de classes, Engels precisa a propósito da redação do programa socialista de Erfurt de 1891: 'E é preciso dizer que, dado o antagonismo social, também as classes dominantes são extropiadas tanto intelectualmente como fisicamente, e repito: ainda mais do que as classes oprimidas' $^{12}$ (Dangeville Apud Marx \& Engels, 1978: p.38)

${ }^{13}$ Marx em o "Livro Primeiro de O Capital", capítulo XIII, aponta que a tecnologia manifestava uma atitude ativa do homem para com o seu meio natural, a vitória da humanidade sobre a natureza. Esse processo significava a produção da sua vida e, por conseguinte, das suas condições sociais de vida e das representações espirituais que delas derivam. É como fruto dessas reflexões que, em trabalho conjunto com Engels em o "Manifesto Comunista", analisa as contradições que se manifestam pelo avanço tecnológico por um lado, acompanhado pela intensa degradação social por outro.

14 Marx denunciou essa questão quando analisou a educação na maquinaria e a grande indústria, demonstrando o analfabetismo imperante até entre os professores. Muitos certificados de freqüência escolar 
dos alunos são assinados apenas com uma cruz, por não serem eles mesmos alfabetizados. Referenciando os relatórios de um inspetor do trabalho no século XIX, aponta a situação das escolas e seus alunos na Inglaterra. Ao visitar uma dessas escolas expedidoras de certificados fiquei tão chocado com a ignorância do mestre-escola que lhe disse: 'Por favor, o senhor sabe ler? Sua resposta foi : Ah! Algo (summat). E, como justificativa, acrescentou: De todos os modos estou à frente dos meus alunos' (...) A primeira escola que visitamos era mantida por uma Mrs. Ann Killin. Quando lhe pedi para soletrar o sobrenome, ela logo cometeu um erro ao começar com a letra C, mas, corrigindo-se imediatamente, disse que ser sobrenome começava com K. Olhando sua assinatura nos livros de assentamento escolares, reparei, no entanto, que ela o escrevia de vários modos, enquanto sua letra não deixava nenhuma dúvida quanto a sua incapacidade de lecionar. Ela mesma também reconheceu que não sabia manter o registro (...) Numa segunda escola, encontrei uma sala de aula de 15 pés de comprimento e 10 pés de largura e nesse espaço contei 75 crianças que estavam grunhindo algo ininteligível. Não é, porém, apenas nessas covas lamentáveis que as crianças recebem certificados escolares, mas nenhuma instrução, pois, em muitas escolas onde o professor é competente, os esforços dele são de pouca valia em face ao amontoado atordoante de crianças de todas as idades, a partir de 3 anos. Sua receita, mísera no melhor dos casos, depende totalmente do número de pence, recebidos do maior número possível de crianças que seja possível empilhar num quarto. A isso acresce o parco mobiliário escolar, carência de livros e outros materiais didáticos, bem como o efeito deprimente, sobre as pobres crianças, de uma atmosfera fechada e fétida. Estive em muitas dessas escolas, onde vi séries inteiras de crianças não fazendo absolutamente nada; e isso é certificado como freqüência escolar e, na estatística oficial, tais crianças figuram como sendo educadas (educated) (Marx, 1988: 25). Marx retrata a educação oferecida aos trabalhadores nas indústrias metalúrgicas de estamparia inglesa, problematizando que em uma sociedade de classes organizada nas fronteiras da reificação crescente, o acesso ao conhecimento é heterogêneo e diversificado. Toda criança, antes de ser empregada numa dessas estamparias, deve ter freqüentado a escola ao menos por 30 dias e por não menos de 150 horas durante 6 meses que precedem imediatamente o primeiro dia de seu emprego. Durante a continuidade de seu emprego na estamparia, precisa igualmente freqüentar a escola por um período de 30 dias e de 150 horas a cada período semestral. [...] Em circunstâncias normais, as crianças freqüentam a escola de manhã e à tarde por 30 dias, 5 horas por dia e, após o decurso dos 30 dias, quando estatutária global de 150 horas foi atingida, quando eles, para usar seu linguajar, acabaram o seu livro, voltam para a estamparia, onde ficam de novo 6 meses até que vença outro prazo de freqüência escolar, e então ficam novamente na escola até que acabem o livro novamente. (...) Muitos jovens que freqüentavam a escola durante as 150 horas requeridas, quando voltam ao término de 6 meses de permanência, estão no mesmo ponto em que estavam no começo. (...) Eles naturalmente perderam tudo quanto tinham adquirido com sua freqüência anterior à escola (Marx, 1988: 26).

${ }^{15}$ O diálogo de Marx com Owen em os "Grundisse" elucida essa questão, afirmando que na relação entre a burguesia e os trabalhadores, os últimos são de fato os seus [...] servidores, como lhes chama, são de fato os seus escravos, e estão reduzidos a uma degradação sem apelo; a maior parte deles estão reduzidos a uma degradação sem apelo; a maior parte deles estão privados de saúde, de conforto doméstico, de repouso, e das sãs e livres alegrias de outrora. O excessivo dispêndio das forças, devido às suas ocupações monótonas e intermináveis, incita-os e hábitos de imoderação e torna-os defeituosos no pensamento ou na reflexão. Não podem entregar-se a nenhum prazer físico, intelectual ou moral, salvo os da mais baixa espécie; todos os verdadeiros prazeres da vida estão muito longe deles. Numa palavra, a existência que leva a maior parte dos operários no atual sistema não vale a pena ser vivida (Marx, 1980: 62-63).

16 A máquina já não tem nada de comum com o instrumento do trabalhador individual. A atividade manifesta-se muito mais como pertencente à máquina, ficando o operário a vigiar a ação da máquina e protegê-la de avarias. Com a ferramenta era diferente. O trabalhador animava a ferramenta com sua arte e criatividade. Com efeito, a máquina é que passa a ter virtuosidade, pois as leis mecânicas em seu interior dotaram-na de alma. (...) Nos numerosos pontos do sistema mecânico, o trabalho aparece como corpo consciente, sob a forma de alguns trabalhadores vivos. Dispersos, submetidos ao processo de conjunto da maquinaria, não forma mais do que um elemento do sistema, cuja unidade não reside nos trabalhadores vivos, mas na maquinaria viva (ativa) que, em relação à atividade isolada e insignificante do trabalho vivo, aparece como um organismo gigantesco (Marx, 1980: 38-39).

Recebido em: $\quad 22 / 02 / 11$

Aprovado em: $\quad 25 / 03 / 11$

Revista HISTEDBR On-line, Campinas, número especial, p. 271-282, abr2011 - ISSN: 1676-2584 